\title{
Highlight report: high-resolution mass spectrometry
}

\author{
Meinolf Blaszkewicz ${ }^{1}$
}

Received: 18 October 2016 / Accepted: 26 October 2016 / Published online: 4 November 2016

(C) Springer-Verlag Berlin Heidelberg 2016

Recently, Hans Maurer and Markus Meyer from Saarland University contributed a comprehensive review article about the current status and future perspectives of highresolution mass spectrometry (HRMS) to the Archives of Toxicology (Maurer and Meyer 2016). The authors illustrate how HRMS became an indispensable tool in analytical toxicology, offering high power of identification and the possibility of quantitative measurements in very low concentration ranges. HRMS has already been developed in the early 1960 and meanwhile has intensively been used in protein analysis (Lesur and Domon 2015; Sajic et al. 2015). Fields of HRMS application discussed by Maurer and Meyer include:

- Elucidation of metabolite structures in drug metabolism studies (Meyer and Maurer 2012; Castaneto et al. 2015)

- Studies of pharmacokinetics (Richter et al. 2016; Wink et al. 2016)

- Screening for pharmaceuticals, drugs of abuse and toxins, making use of the flexibility of HRMS to add further compounds easily to existing screening approaches (Peters 2014; Patteet et al. 2015)

- Quantification of pharmaceuticals, drugs of abuse and toxins, where a reliable quantification is required for clinical decisions or forensic consequences (Maurer 2007). Here, LC-HRMS/MS has become the most applied technique for multi-target quantification (Meyer et al. 2014; Meyer and Maurer 2016).

Meinolf Blaszkewicz

blaszkewicz@ifado.de

IfADo - Leibniz Research Centre for Working Environment and Human Factors at TU Dortmund, Ardeystr. 67,

44139 Dortmund, Germany
In recent years, analytical methods have been further developed in various fields of toxicology, such as metabolite identification (Ali et al. 2015; Huybrechts et al. 2015; Godoy et al. 2013), characterization of volatile organic compounds (Schubert et al. 2015; Hutzler et al. 2014), DNA-adducts ( $\mathrm{Hu}$ et al. 2015), inflammatory mediators (Patel et al. 2015; Kim et al. 2013), characterization of plant extracts (Khan et al. 2014; Simlai et al. 2014; Naghiloo et al. 2012) and metabolomics (Fang and Gonzalez 2014; Beger et al. 2015; Pink et al. 2014). The relevant basic principles of high-resolution mass spectrometry are given by Pleil and Isaacs (2016). Considering the rapid developments in mass spectrometry based technologies, the present review of Maurer and Meyer with its well-structured and realistic discussion of possibilities and limitations of the available techniques is of high interest to anyone interested in this field of analytical toxicology.

\section{References}

Ali N, Blaszkewicz M, Degen GH (2015) Occurrence of the mycotoxin citrinin and its metabolite dihydrocitrinone in urines of German adults. Arch Toxicol 89(4):573-578. doi:10.1007/ s00204-014-1363-y

Beger RD, Bhattacharyya S, Yang X, Gill PS, Schnackenberg LK, Sun J, James LP (2015) Translational biomarkers of acetaminophen-induced acute liver injury. Arch Toxicol 89(9):14971522. doi:10.1007/s00204-015-1519-4

Castaneto MS, Wohlfarth A, Desrosiers NA, Hartman RL, Gorelick DA, Huestis MA (2015) Synthetic cannabinoids pharmacokinetics and detection methods in biological matrices. Drug Metab Rev 47(2):124-174. doi:10.3109/03602532.2015.1029635

Fang ZZ, Gonzalez FJ (2014) LC-MS-based metabolomics: an update. Arch Toxicol 88(8):1491-1502. doi:10.1007/s00204-014-1234-6

Godoy P, Hewitt NJ, Albrecht U, Xu JJ, Yarborough KM, Hengstler JG (2013) Recent advances in 2D and 3D in vitro systems using primary hepatocytes, alternative hepatocyte sources and 
non-parenchymal liver cells and their use in investigating mechanisms of hepatotoxicity, cell signaling and ADME. Arch Toxicol 87(8):1315-1530. doi:10.1007/s00204-013-1078-5

Hu CW, Cooke MS, Tsai YH, Chao MR (2015) 8-Oxo-7,8-dihydroguanine and 8-oxo-7,8-dihydro-2'-deoxyguanosine concentrations in various human body fluids: implications for their measurement and interpretation. Arch Toxicol 89(2):201-210. doi:10.1007/s00204-014-1255-1

Hutzler C, Paschke M, Kruschinski S, Henkler F, Hahn J, Luch A (2014) Chemical hazards present in liquids and vapors of electronic cigarettes. Arch Toxicol 88(7):1295-1308. doi:10.1007/ s00204-014-1294-7

Huybrechts B, Martins JC, Debongnie P, Uhlig S, Callebaut A (2015) Fast and sensitive LC-MS/MS method measuring human mycotoxin exposure using biomarkers in urine. Arch Toxicol 89(11):1993-2005. doi:10.1007/s00204-014-1358-8

Khan MS, Singh M, Khan MA, Arya DS, Ahmad S (2014) Scientific validation of cardioprotective attribute by standardized extract of Bombyx mori against doxorubicin-induced cardiotoxicity in murine model. EXCLI J 13:1043-1054

Kim MJ, Yang KW, Kim SS, Park SM, Park KJ, Kim KS, Choi YH, Cho KK, Lee NH, Hyun CG (2013) Chemical composition and anti-inflammatory effects of essential oil from Hallabong flower. EXCLI J 12:933-942

Lesur A, Domon B (2015) Advances in high-resolution accurate mass spectrometry application to targeted proteomics. Proteomics 15(5-6):880-890. doi:10.1002/pmic.201400450

Maurer HH (2007) Demands on scientific studies in clinical toxicology. Forensic Sci 165(2-3):194-198

Maurer HH, Meyer MR (2016) High-resolution mass spectrometry in toxicology: current status and future perspectives. Arch Toxicol 90(9):2161-2172. doi:10.1007/s00204-016-1764-1

Meyer MR, Maurer HH (2012) Current status of hyphenated mass spectrometry in studies of the metabolism of drugs of abuse, including doping agents. Anal Bioanal Chem 402(1):195-208. doi:10.1007/s00216-011-5331-6

Meyer MR, Maurer HH (2016) Review: LC coupled to low- and highresolution mass spectrometry for new psychoactive substance screening in biological matrices-Where do we stand today? Anal Chim Acta 13(927):13-20. doi:10.1016/j.aca.2016.04.046

Meyer MR, Helfer AG, Maurer HH (2014) Current position of highresolution MS for drug quantification in clinical \& forensic toxicology. Bioanalysis 6(17):2275-2284. doi:10.4155/bio.14.164

Naghiloo S, Movafeghi A, Delazar A, Nazemiyeh H, Asnaashari S, Dadpour MR (2012) Ontogenetic variation of volatiles and antioxidant activity in leaves of Astragalus compactus Lam. (Fabaceae). EXCLI J 11:436-443
Patel NK, Khan MS, Bhutani KK (2015) Investigations on Leucas cephalotes (Roth.) Spreng for inhibition of LPS-induced pro-inflammatory mediators in murine macrophages and in rat model. EXCLI J 14:508-516. doi:10.17179/excli2014-667

Patteet L, Cappelle D, Maudens KE, Crunelle CL, Sabbe B, Neels $\mathrm{H}$ (2015) Advances in detection of antipsychotics in biological matrices. Clin Chim Acta 20(441):11-22. doi:10.1016/j. cca.2014.12.008

Peters FT (2014) Recent developments in urinalysis of metabolites of new psychoactive substances using LC-MS. Bioanalysis 6(15):2083-2107. doi:10.4155/bio.14.168

Pink M, Verma N, Rettenmeier AW, Schmitz-Spanke S (2014) Integrated proteomic and metabolomic analysis to assess the effects of pure and benzo[a]pyrene-loaded carbon black particles on energy metabolism and motility in the human endothelial cell line EA.hy926. Arch Toxicol 88(4):913-934. doi:10.1007/ s00204-014-1200-3

Pleil JD, Isaacs KK (2016) High-resolution mass spectrometry: basic principles for using exact mass and mass defect for discovery analysis of organic molecules in blood, breath, urine and environmental media. J Breath Res 10(1):012001. doi:10.1088/1752-7155/10/1/012001

Richter LH, Kaminski YR, Noor F, Meyer MR, Maurer HH (2016) Metabolic fate of desomorphine elucidated using rat urine, pooled human liver preparations, and human hepatocyte cultures as well as its detectability using standard urine screening approaches. Anal Bioanal Chem 408(23):6283-6294. doi:10.1007/s00216-016-9740-4

Sajic T, Liu Y, Aebersold R (2015) Using data-independent, highresolution mass spectrometry in protein biomarker research: perspectives and clinical applications. Proteomics Clin Appl 9(3-4):307-321. doi:10.1002/prca.201400117

Schubert J, Müller FD, Schmidt R, Luch A, Schulz TG (2015) Waterpipe smoke: source of toxic and carcinogenic VOCs, phenols and heavy metals? Arch Toxicol 89(11):2129-2139. doi:10.1007/ s00204-014-1372-x

Simlai A, Rai A, Mishra S, Mukherjee K, Roy A (2014) Antimicrobial and antioxidative activities in the bark extracts of Sonneratia caseolaris, a mangrove plant. EXCLI J 13:997-1010

Wink CS, Michely JA, Jacobsen-Bauer A, Zapp J, Maurer HH (2016) Diphenidine, a new psychoactive substance: metabolic fate elucidated with rat urine and human liver preparations and detectability in urine using GC-MS, LC-MSn, and LC-HR-MSn. Drug Test Anal. 8(10):1005-1014. doi:10.1002/dta.1946 